\title{
New strategies for novel antibiotics: peptides targeting bacterial cell membranes
}

\author{
Karl Lohner \\ Institute of Biophysics and Nanosystems Research, Austrian Academy of Sciences, Graz, Austria
}

\begin{abstract}
Membranes are targets of host defence or antimicrobial peptides, effector molecules of innate immunity that evolved in nature to contend with invaders as an active system of defence. The different physicochemical properties of the lipids found in biological membranes allow antimicrobial peptides to discriminate between bacterial and mammalian cell membranes. Such cationic amphipathic peptides will interact predominantly with negatively charged lipids exposed on the outer leaflet of bacterial cell membranes. The molecular mechanism(s) of membrane rupture mutually depends on the nature of the peptide and membrane lipid composition. Biophysical studies demonstrated a complex behavior in terms of membrane perturbation, which can range from pore formation to micellization (carpet model). Peptides aligned parallel to the membrane surface can induce a quasiinterdigitated structure in the gel phase, while depending on the hydrophobic matching of the lipid bilayer core and the peptide membrane thinning or thickening can be observed in the fluid phase. As a consequence, besides of peptide-lipid pores, formation of peptide-enriched membrane domains and promotion of cubic structures can be observed, which adversely affect membrane integrity and function. A strategy using the membrane damaging properties of these peptides will form the basis for the development of such peptides as potential novel antibiotic drugs.
\end{abstract}

Key words: Biomembrane mimetics - Membrane domains — Lipid segregation — Interdigitation - Cubic phases

\section{The need of novel strategies for the treatment of bacterial infections}

Nowadays, we face a worldwide re-emergence of infectious diseases and a rapid increase in pathogenic bacteria that are multi-resistant to commercially available antibiotics. The need of effective antibiotic treatment relates especially to the ageing population, to patients that undergo cytostatic therapy and to immunocompromised patients. Furthermore, in the area of hospital infection control there is an increasing concern regarding the rapid emergence of drug-resistant strains, which can pass their resistance genes to other bacteria (Hawkey 2008). The dramatic situation is emphasized by observations that antibiotic resistant bacteria, expected to be confined to hospitals such as e.g. methicillin resistant

Correspondence to: Karl Lohner, Institute of Biophysics and Nanosystems Research, Austrian Academy of Sciences, Schmiedlstrasse 6, A-8042 Graz, Austria

E-mail: karl.lohner@oeaw.ac.at
Staphylococcus aureus (MRSA), the most common cause for nosocomial wound infections worldwide, increasingly occur outside hospital areas (Enserink 2003). Since the 1980s, the number of MRSA strains increased from close to zero up to $70 \%$ in Japan and the Republic of Korea and to around $30 \%$ in the USA (Smith and Coast 2002). The proportions of MRSA of total S. aureus infections also increased in the European countries. Reports from the "European antimicrobial resistance surveillance system" (EARSS 2006, annual report), demonstrated that in general lower level of MRSA (up to 5\%) are found in Scandinavia, Denmark and the Netherlands, while Southern Europe, France and Great Britain show proportions between 25-50\%.

When bacteria become resistant to antibiotics, treatment has to be switched to more costly second-line antibiotics resulting also in considerable economic effects. Thus, MRSA infections are generally treated with antibiotics of last resort, mostly therapeutics of the group of glycopeptides, where vancomycin serves as the prototype (Fluit and Schmitz 2003). However, a first vancomycin resistant S. aureus 


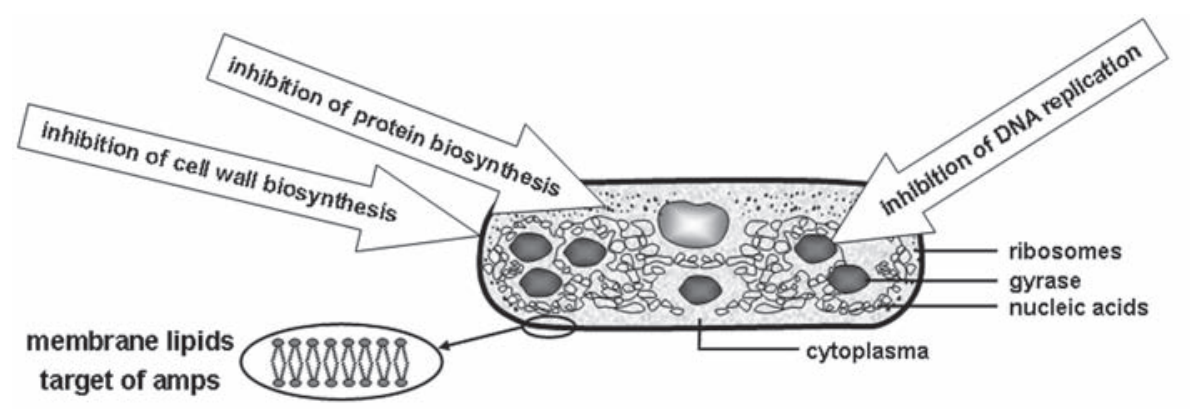

Figure 1. Scheme of a bacterium indicating major targets of conventional antibiotics that bind to specific receptors interfering with cell membrane processes, while antimicrobial peptides (amps) interact predominantly with the lipid bilayer of the cytoplasmic membrane without specific receptors leading to membrane disruption.

strain was identified in Japan already in 1996 (Chang et al. 2003; Fluit and Schmitz 2003). Although a number of MRSA strains are still susceptible to vancomycin and other glycopeptides, decreased vancomycin susceptibility has now emerged within all pandemic MRSA lineages (Howe et al. 2004). In the annual report of 2006, the EARSS listed nine vancomycin intermediate resistant $S$. aureus strains within Europe (EARSS).

Hence the World Health Organization ranked antibiotic resistance as a priority disease and published a comprehensive document "Global Strategy for the Containment of Antimicrobial Resistance" suggesting some guidance on the implementation of interventions such as improving the use of antibiotics, i.e. to avoid excessive and often inappropriate use of antibiotics in human and animal health care, enforcing regulations, strengthening health-care systems and encouraging the development of novel antibiotics. Latter is a pressing need, because the number of new antibiotics markedly decreased, as reflected in the almost linear decline of antibacterial new molecular entities within the last twenty years. However, new drugs with similar structures relative to existing antibiotics will remain highly vulnerable to bacterial resistance mechanisms and will have only a limited life span. With oxazolidinones and daptomycin, approved lately by the U.S. Food and Drug Administration, only two new classes were introduced on the market in the last three decades (Nordberg et al. 2005).

Conventional antibiotics bind to specific receptors interfering with cell membrane processes such as cell wall or protein biosynthesis and DNA replication (Fig. 1, Table 1). The main challenge of a rational design of new drugs based on protein receptor active sites is the identification of this site as well as molecules that bind to it. Obviously, this requires detailed knowledge of the active site and although sequence and structure information on proteins doubles every three years, the majority relates to new proteins with unknown functions. Nevertheless, new drugs based on this strategy will still be prone to induce resistance. Therefore, alternative agents with novel mechanism(s) of action have to be developed (Lohner 2001a). One emerging strategy is based on host defence peptides, effector molecules of innate immunity that can provide a first line of defence against a substantial array of pathogenic microorganisms. These peptides have evolved in nature to contend with invaders as an active system of defence (Boman 1991; Ganz and Lehrer 2001). Within the last decade the number of such peptides being isolated and characterized increased immensely showing a wide variety of structures ranging from $\alpha$-helical, $\beta$-sheet, extended to loop among the different peptides (Powers and Hancock 2003). These antimicrobial peptides usually exhibit a high specificity towards

Table 1. Inhibition of cellular processes of common conventional antibiotics

\begin{tabular}{|l|l|}
\hline Cellular target & Commercial antibiotic \\
\hline Cell wall biosynthesis & Bacitracin, Carbapenems, Cephalosporins, Fosfomycin, Monobactams, Penicillins, Vancomycin \\
\hline $\begin{array}{l}\text { Protein biosynthesis } \\
\text { (50S inhibitors) }\end{array}$ & Clindamycin, Chloramphenicol, Erythromycin \\
\hline $\begin{array}{l}\text { Protein biosynthesis } \\
\text { (30S inhibitors) }\end{array}$ & Amikacin, Gentamycin, Spectinomycin, Streptomycin, Tetracycline, Tobramycin \\
\hline DNA gyrase & Quinolones \\
\hline RNA polymerase & Rifampin \\
\hline Folic acid metabolism & Sulfonamides, Trimethoprim \\
\hline
\end{tabular}


their target cell, i.e. exhibiting toxicity, which is restricted to microorganisms, and thus represent a novel source for the development of antibiotic agents. In contrast to conventional antibiotics antimicrobial peptides predominantly act without specific receptors, but interact with the lipid matrix of bacterial cell membranes (Fig. 1). It should be noted, however, that antimicrobial peptides may have also specific targets such as lantibiotics, which bind to lipid II, a precursor of the peptidoglycan layer, either resulting in membrane rupture by pore formation or preventing cell wall biosynthesis (Hasper et al. 2006). In addition, some peptides traverse the membrane and bind to intracellular targets, as described in a recent review (Hale and Hancock 2007). Nevertheless, as will be outlined in more detail below, these cationic amphipathic peptides composed of 10-40 amino acid residues particularly target negatively charged lipids, which are exposed on the outer leaflet of bacterial cell membranes. In these cases bacterial resistance is less likely to occur owing to the nature of the target, since substantial modification of the lipid composition would affect bacterial cell viability. Degradation of antimicrobial peptides by proteases may be a concern, but also imposes problems, as most peptides are created from nondescript sequences of amino acids and hence lack unique epitopes as recognition site of proteases. In addition, multi-cellular organisms attack bacteria with a number of peptides of different structural classes, and therefore, degradation of one peptide might not be sufficient to combat such an attack (Zasloff 2002). Another advantage of antimicrobial peptides in respect of bacterial resistance is that they can destroy bacteria within minutes. This fast killing rate, being faster than the growth rate of bacteria, enables an effective defence (Boman 2003).

\section{Membrane lipids as target for antimicrobial peptides}

The structural unit of biological membranes is a phospholipid bilayer that acts as a fundamental permeability barrier. The concept of a characteristic lipid composition for a given cell membrane is well accepted, although changes in lipid composition may occur depending on environmental conditions. Gram-positive bacteria have a simple lipid bilayer membrane protected by a lipoteichoic acid layer, while the cell envelope of Gram-negative bacteria is a complex structure consisting of an inner membrane, an unique outer membrane layer and an intervening layer of peptidoglycan in the periplasmic space (Fig. 2). The outer membrane of Gram-negative bacteria has a distinctive, highly asymmetric composition with the lipopolysaccharides (or endotoxin) located exclusively in its outer leaflet. Negatively charged lipids such as phosphatidylglycerol (PG) and diphosphatidylglycerol or cardiolipin and the zwitterionic phosphatidylethanolamine (PE) constitute to a large extent the cytoplasmic membrane of both bacterial classes (Lohner 2001b and references therein).

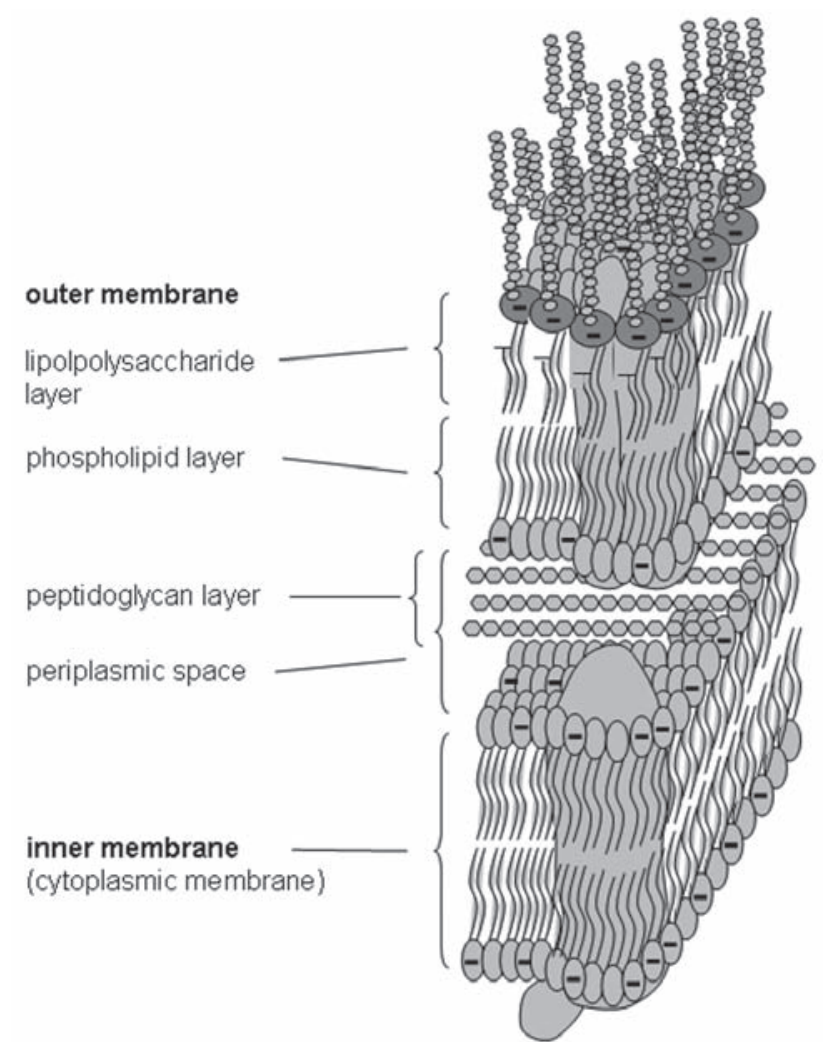

Figure 2. Schematic presentation of the membrane architecture of Gram-negative bacteria consisting of an outer membrane with an asymmetric distribution of lipolpolysaccharides and phospholipids, predominantly PE, and a cytoplasmic or inner membrane. Gram-positive bacteria have only a cytoplasmic membrane protected by a peptidoglycan layer, which is also found in the periplasmic space of Gram-negative bacteria. PG is the most abundant negatively charged phospholipid species found in both bacteria.

The archetype of mammalian cell membranes is represented by the plasma membrane of red blood cells, which lipid composition and distribution was studied in most detail (Bevers et al. 1999). This membrane consists of about $60 \%$ of phospholipids and $25 \%$ of cholesterol with an asymmetric distribution of phospholipids between the outer and inner lipid leaflet of the bilayer exposing the neutral phosphatidylcholine and sphingomyelin phospholipids to the extracellular side (Rothman and Leonard 1977; Yorek 1993).

In a simplified view that means that antimicrobial peptides will face a negatively charged membrane surface in the case of bacteria and a neutral one in the case of mammalian cells, which will result in a lower affinity of these cationic peptides towards host cells as compared to bacteria. This led to the concept of lipid discrimination by host defence peptides (Lohner et al. 1997; Lohner 2001b), whereby the lipid composition strongly influences the molecular mechanisms of membrane damage 
(Lohner and Blondelle 2005; Bechinger and Lohner 2006; Sevcsik et al. 2008). Initial work in this field by our group and others showed that a number of antimicrobial peptides indeed interact preferentially with negatively charged phospholipids. For example, the $\beta$-sheet peptides such as tachyplesin (Nakamura et al. 1988), human neutrophil peptide (White et al. 1995; Lohner et al. 1997) or protegrin-1 from porcine leukocytes (Latal et al. 1996) discriminate between anionic and choline phospholipids, the former mimicking bacterial and the latter mammalian cell membranes. The same behavior was found for the $\alpha$-helical frog skin peptides (PGLa) (Latal et al 1997; Konovalov et al. 2002) and magainin, which killed more effectively Gram-negative bacteria containing an inner membrane with higher amounts of PG (Matsuzaki et al. 1997). Moreover, the biologically less active [Glu-32] mutant of nisin Z, obtained by introducing a negative charge in the cationic $\mathrm{C}$-terminus of this peptide, inserted less efficiently into monolayers composed of negatively charged cardiolipin and PG (Breukink et al. 1997). These early observations clearly emphasize the role of electrostatic interactions as a major determinant to trigger the affinity of antimicrobial peptides towards bacterial membranes.

\section{Models of membrane perturbation by antimicrobial peptides}

\section{Carpet model and pore formation}

In the frame of this review less focus will be given to the classical models of pore formation and peptide carpeting (Fig. 3), which have been widely described elsewhere (Matsuzaki 2001; Oren and Shai 2001). In brief, the essential characteristics of the carpet model are adsorption of antimicrobial peptides at the membrane surface until a certain threshold concentration is reached and subsequent insertion of the peptides into the hydrophobic core resulting in permeation/disruption of the membrane. The detailed mechanism of membrane permeation or disruption is less defined. It could be disintegration in a detergent-like manner (Shai 2002; Bechinger and Lohner 2006) or formation of pores (Matsuzaki et al. 1995; Ludtke et al. 1996) and channel like aggregates (Hancock and Rozek 2002).

In the case of pore formation, theoretically no covering of the membrane surface by peptides is necessary, as peptide oligomerization and trans-membrane pore formation may occur below the threshold concentration (Matsuzaki et al. 1998). Nevertheless, it was shown that at low concentrations antimicrobial peptides adopt a surface bound state and transform upon a certain threshold concentration into a pore-forming inserted state, which in model systems is frequently observed around a lipid-to-peptide molar ratio of $20: 1$ (Huang 2006). It was suggested that insertion of the peptides is driven by the entropy of the membrane adsorbed

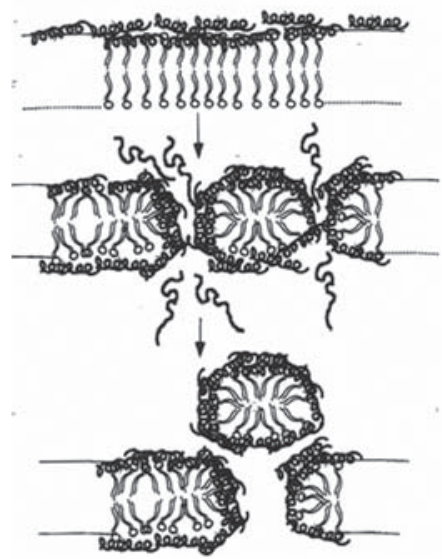

carpet model

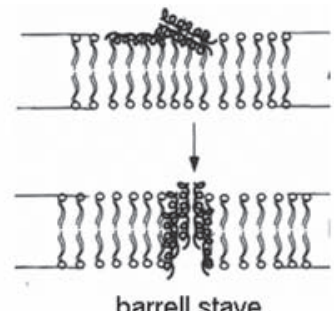

barrell stave

toroidal

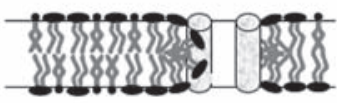

pore formation
Figure 3. Modes of action of antimicrobial peptides - carpet model and pore formation (adapted and modified from Oren and Shai (2001)). Barrell stave and toroidal pore are shown. Latter involves phospholipids in its formation. For details see text.

peptides (Pabst et al. 2007). The structure of these peptide pores as well as the process of pore formation was extensively studied predominantly by the group of Matsuzaki and of Huang, respectively. An involvement of lipids in the formation of a peptide pore was proposed based on the observation that magainin 2 induced rapid lipid flip-flop coupled with pore formation (Matsuzaki et al. 1996). The structure of such a phospholipid-magainin pore was solved by neutron scattering (Ludtke et al. 1996). In this complex - named toroidal or wormhole pore - the phospholipids bend from the membrane interface towards the hydrophobic interior and are intercalated between the long axis of the peptide molecules, which are oriented perpendicular to the bilayer plane (Fig. 3). Subsequent studies revealed that other peptides such as protegrin-1 (Heller et al. 2000) or the lytic bee venom peptide, melittin (Yang et al. 2001) arrange in such a pore. A pore of the barrel-stave type was described for alamethicin (He et al. 1996).

In addition, X-ray studies showed that the thickness of the fluid bilayer decreases almost linearly with increasing peptide concentration (Chen et al. 2003). In the fluid phase, the bending rigidity of lipid bilayers is about one order of magnitude lower than in the gel phase. Therefore the bilayer may respond elastically to a peptide embedded in the bilayer interface leading to a local membrane deformation and thinning upon insertion of the peptides (Huang 2006; Li and Salditt 2006; Pabst et al. 2007). Recently, we have shown, however, that pore formation by antimicrobial peptides does not necessarily relate to membrane thinning. In contrast, an acyl chain dependant behavior was observed for the 
antimicrobial frog skin peptide PGLa showing a membrane thickening for liposomes composed of diC14:0 PG (DMPG) and diC16:0 PG (DPPG) (Pabst et al. 2008). No changes in the overall bilayer structure for the longer chain diC18:0 PG (DSPG) was detected. This can be explained by considering the length of the $\alpha$-helical peptide and hydrophobic matching with the lipid bilayer core (Killian 2003) demonstrating that PGLa remarkably fits into the hydrophobic core of DSPG. In case of DPPG the peptide cannot be accommodated with its full length and thus the lipid responds to the insertion of the peptide by stretching of the hydrocarbon chains leading to an increase of membrane thickness by about $2 \AA$ (Fig. 4). Such a behavior was reported earlier for phosphatidylcholine (PC) bilayers in the presence of hydrophobic model peptides of various length with $\mathrm{N}$ - and C-terminal interface anchors (de Planque et al. 1998). The increase in bilayer thickness was less pronounced for DMPG than for DPPG, which may be due to the entropic penalty of increasing the membrane thickness to a value that can accommodate PGLa with its helical axis normal to the bilayer surface. Therefore, tilting of the peptide with respect to the bilayer normal, as shown for dimyristoyl-PC/dimyristoyl-PG bilayers (Strandberg et al. 2006), may be an energetically favorable compromise. These results demonstrate that membrane thinning cannot be taken generally as the hallmark of pore formation by antimicrobial peptides (Pabst et al. 2008). This is further supported by observations that membrane thinning of the fluid lipid bilayer was also observed for the human peptide LL-37 (Sevcsik et al. 2008), for which no pore formation has been reported so far. This peptide, almost twice as long as
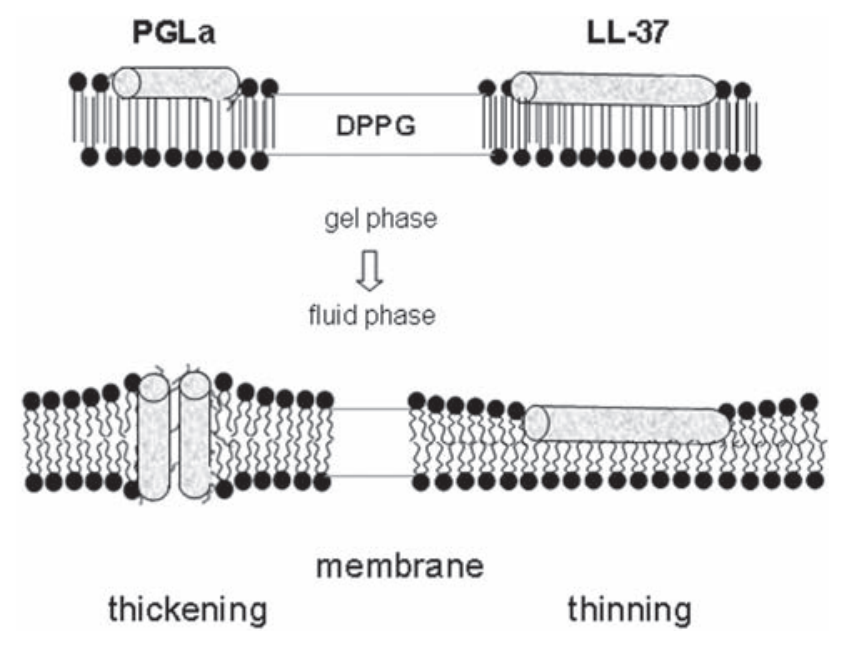

Figure 4. Both $\alpha$-helical peptides, PGLa and LL-37, induce a quasiinterdigitated phase in DPPG bilayers in the gel- phase, while in the fluid phase owing to different peptide alignments within the membrane PGLa leads to membrane thickening and LL-37 to membrane thinning.

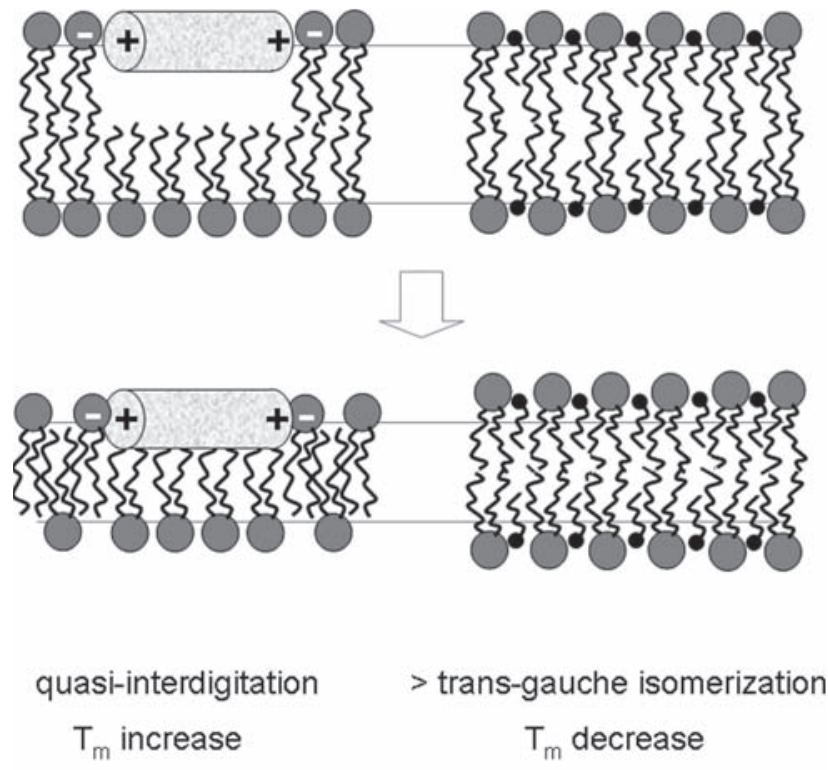

Figure 5. Induction of "free volume" (void) by incorporation of peptides aligned parallel at the membrane interface (left) and by small amphiphilic molecules such as e.g. alcohols or tertiary amines (right). Modes of compensation and their effect on the main transition temperature $\left(\mathrm{T}_{\mathrm{m}}\right)$ are indicated in the panel (for details see text).

PGLa (37 vs. 21 amino acid residues) seemingly cannot adopt an energetically favorable bilayer-spanning position owing to the large hydrophobic mismatch between peptide length and hydrocarbon bilayer core (Fig. 4). However, in the gel phase both PGLa and LL-37 induced a quasi-interdigitated phase (Fig. 4) being most pronounced for the long-chain DSPG (Sevcsik 2007; Pabst et al. 2008).

\section{"Free volume" model}

Induction of an interdigitation of hydrocarbon chains in the gel phase can be understood in terms of the "free volume" (void) model, as described earlier for small amphiphilic molecules such as e.g. alcohols, anesthetics or surfactants (Lohner 1991; Balgavý and Devínsky 1996). It has been suggested that the lateral expansion of a phospholipid bilayer caused by the intercalation of amphiphilic molecules between phospholipid molecules and the mismatch between their hydrocarbon chain lengths results in the creation of voids in the hydrophobic region of the bilayer (Fig. 5). However, formation of free volume within the hydrophobic core of the bilayer is energetically unfavourable and hence the system will rearrange in a way that hydrophobic interactions are maximized. Elimination of the free volume can be achieved via increased trans-gauche isomerisation of the hydrocarbon chains of the neighboring lipids or by interdigitation 
of the hydrocarbon chains. Both will result in a decrease in the bilayer thickness. For example, the effects of non-ionic surfactants ( $N$-alkyl- $N, N$-dimethylamine- $N$-oxides) on the bilayer thickness of phosphatidylcholine model membranes and the lipid surface area at the bilayer-aqueous interface were shown to depend on the hydrophobic mismatch between the alkyl chain of the amphiphilic molecule and the acyl chain of PC (Balgavý et al. 1993; Karlovská et al. 2004). Interestingly, these tertiary amines exhibit besides other biological activities also an antimicrobial activity (Devínsky et al. 1990; Balgavý and Devínsky 1996; Glover et al. 1999). The biological activities of these surface active compounds increase progressively with increasing chain length up to a critical point of a chain length, beyond which the compounds cease to be active, the so-called cut-off effect. The reduced activity in case of long hydrocarbon chain substituents is due to the decrease in the difference between the hydrocarbon chain length of the phospholipid and amphiphile and by the increase in their van der Waals attraction, while short substituent amphiphiles are mobile and exchange between multiple binding sites in the bilayer (Balgavý et al. 2001). Very short-chain amphiphilic molecules like ethanol were shown to induce a biphasic behavior in saturated PC membranes (Rowe 1983), i.e., at low concentrations of alcohols the gel to fluid phase transition temperature is decreasing, while it is increasing at higher alcohol concentrations. Simon and Mclntosh (1984) demonstrated that this biphasic behavior is due to the formation of an interdigitated phase, where the lipid acyl chains from opposing monolayers fully interpenetrate with a concomitant increase in headgroup area and van der Waals contacts in the hydrocarbon core. At very high concentrations, the hydrophobic mismatch between the amphiphiles and phospholipids can result in bilayer destabilization and formation of non-bilayer phases and mixed micelles (Kragh-Hansen et al. 1998; Uhríková et al. 2001; Hrubšová et al. 2003). These effects are probably the cause of the biocidal properties of such non-ionic detergents, but can also be important for the isolation, purification and crystallization of membrane proteins.

Considering now the situation, where peptides are aligned parallel to the membrane plane, voids will be also created in the hydrophobic core of the membrane (Lohner and Blondelle 2005). The extent of this perturbation will depend on a number of parameters such as the concentration, molecular size and aggregation state of the peptide, which determine the lateral area occupied by the peptide in the membrane, as well as on the membrane penetration depth of the peptide. Latter is influenced by the hydrophobic angle of the peptide and in particular by electrostatic interaction between peptide and lipid. At certain conditions this perturbation cannot be compensated by increased trans-gauche isomerization of the acyl chains of the lipids as seen for smaller amphipathic molecules, but by moving the opposing monolayer of the bilayer towards the hydrophobic face of the peptide, which results in a quasi-interdigitated structure (Fig. 5). The formation of such a structure was verified by biophysical studies, whereby the strongly reduced membrane thickness was deduced from small-angle X-ray diffraction experiments (Sevcsik et al. 2007). Furthermore, electron spin resonance spectroscopy data demonstrated a reduced mobility of the hydrocarbon chains near the terminal methyl group of this peptide-enriched domain (Sevcsik et al. 2007) and microcalorimetric experiments showed that the phase transition temperature of the peptide induced quasi-interdigitated phase shifts to higher values (Latal et al. 1997; Sevcsik et al. 2007; Pabst et al. 2008). Regarding penetration depth of peptides it was shown that cationic peptides penetrate less deeply into the hydrophobic core of anionic as compared to neutral bilayers (Dathe et al. 2002). In agreement with this observation, LL-37 induced a quasi-interdigitated phase in negatively charged DPPG but not in zwitterionic DPPC bilayers, where disk-like micelles were found (Sevcsik et al. 2007). The presence of the quasi-interdigitated structure was most prominent for the longest chain PG studied. Moreover, such a structure was observed to some extent also for PCs with increased acyl chain length (diC18:0 PC and diC20:0 PC) (Sevcsik et al. 2007; Pabst et al. 2008). These observations clearly indicate that there is a tight coupling between the peptide properties and those of the lipid bilayer. Very similar effects were also observed for the $\alpha$-helical peptides melittin and PGLa, although differences in the ability and extent of the induction of a quasi-interdigiated structure were found that can be attributed predominantly to the different size of the peptides. For example, in DPPG bilayers at $4 \mathrm{~mol} \%$ of peptide a fully quasi-interdigitated phase was only seen for LL-37 (37 amino acid residues), while in the case of the smaller melittin (26 residues) and PGLa (21 residues) the original bilayer gel phase co-existed in various proportions with the quasi-interdigitated phase. Based on these findings, a general phase diagram was proposed for lipid/peptide mixtures as long as the amphipathic peptides adopt a spatial orientation parallel to the membrane surface taking into account the balance between peptide penetration depth and thickness of the hydrocarbon core of the membrane (Sevcsik et al. 2007). This means that the respective phase boundary for the occurrence of a quasi-interdigitated phase of PC/ peptide mixtures are shifted towards longer chain lengths as compared to PG/peptide mixtures reflecting mainly the deeper penetration of the peptide in PC bilayers.

\section{Membrane-peptide domain formation affecting adversely bacteria}

As outlined above depending on the concentration of the peptide co-existing phases will be found in the lipid bilayer gel phase, which also protrude into the physiologically rel- 
evant fluid bilayer phase with membrane domains differing significantly in their properties in respect of membrane thickness, fluidity and curvature strain. Because of the differences in the physicochemical properties between the lipid bulk phase and the lipid domains enriched with antimicrobial peptide, packing defects will arise at their boundary lines, which lower the membrane permeability barrier. Such defects are obviously present during the thermotropic phase transition from the gel to fluid phase, where enhanced leakage of entrapped solutes in liposomes was observed (Hays et al. 2001). Promotion of domain formation in the presence of antimicrobial peptides was not only observed in mono-component model systems as described above, but also detected in binary lipid mixtures. Adding, cationic antimicrobial peptides (e.g. PGLa, human defensin) to liposomes composed of PE/PG, typical lipids of bacteria, resulted in a depletion of the negatively charged PG from the lipid mixture giving rise to the formation of peptide poor and peptide-rich domains (Lohner et al. 1997; Lohner and Prenner 1999) and a synthetic antimicrobial peptide induced demixing of a cardiolipin and PG mixture (Arouri et al. 2009). Further, aggregation of cateslytin $\beta$-sheets on negatively charged lipids promoted rigid membrane domains (Jean-Francois et al. 2008). The importance of induced lateral phase separation has been specifically proposed as a mechanism contributing to the antimicrobial activity of a designed $\alpha / \beta$ peptide (Epand et al. 2006), a flexible sequence-random polymer that mimics host defence peptides (Epand et al. 2008a) and an oligo-acyl-lysine compound (Epand et al. 2008b). This mechanism is expected to be most important for substances with sequential positive charges contained within a flexible molecule that can adapt to the arrangement of charged groups on the surface of the bacterial cell membrane (Epand and Epand 2009).

Another important aspect is that exclusion of certain lipids, i.e. segregation of anionic lipids from areas of the cell membrane due to their preferential interaction with cationic antimicrobial peptides, will perturb existing membrane domains. Although less investigations have been devoted to the domain formation in bacterial membranes as compared to the numerous studies on lipid rafts in mammalian membranes, there has been increasing evidence that they also exist in bacteria as e.g. demonstrated by chemical cross-linking of lipids (Matsumoto et al. 2006). The presence of domains was also shown by fluorescence studies incorporating pyrene-labelled PE and PG into Escherichia coli and Bacillus subtilis membranes, which indicated that PE and PG are segregated into distinct domains that differ in composition, proteo-lipid interaction and degree of order (Vanounou et al. 2003). Moreover, it was shown that the process of cell division of $E$. coli is dependent on the presence of PE (Mileykovskaya et al. 1998) and that cardiolipin forms large domains in the septal region and poles of $E$. coli
(Mileykovskaya and Dowhan 2000). Therefore, it has been suggested that lipid domains may be important for certain regulatory functions of the cell in particular for bacterial division (Norris and Fishov 2001; Mileykovskaya and Dowhan 2005; Matsumoto et al. 2006). Thus one can speculate that specific interaction of antimicrobial peptides with anionic lipids may have important implications on structure and integrity of membranes and therefore also influence the function of membrane proteins adversely affecting bacteria. Epand and Epand (2009), however, emphasized that clustering of anionic lipids is not likely to be the sole mechanism by which these agents act to kill bacteria, but rather it is an additional contributory factor, as has been also proposed earlier (Lohner and Blondelle 2005).

\section{Antimicrobial peptides promoting non-lamellar structures}

Although the maintenance of a stable bilayer is essential to normal membrane function, it is well-known that cell membranes contain substantial amounts of so-called non-lamellar phase forming lipids (e.g. PE, cardiolipin or monoglucosyldiacylglycerol) and that microorganisms such as E. coli or Acholeplasma laidlawii regulate precisely their lipid composition in a narrow window close to a lamellar to non-lamellar phase boundary (McElhaney 1992; Rilfors et al. 1993; Morein et al. 1996). The presence of such lipids confers upon these membranes a degree of non-lamellar structure forming propensity owing to their molecular properties. In contrast to PG or PC, which are characterized by a cylindrical molecular shape, PE $(>80 \%$ of the total phospholipids in E. coli) is characterized by a truncated cone shape because of its small head group as compared to the cross-section of its hydrocarbon chains (Cullis and de Kruijff 1979; Israelachvili et al. 1980). In terms of the lateral pressure profile throughout the hydrocarbon chain region this means that PG exhibits a uniform lateral pressure, while PE leads to an increase in the lateral pressure in the center of the bilayer (Seddon and Templer 1995; de Kruijff 1997). This in turn results in a bilayer, where the desire for monolayer curvature is physically frustrated. Formation of non-lamellar structures may be understood qualitatively in terms of this lateral pressure profile balancing the repulsive and attractive interactions between the individual lipid molecules within the compound of the lipid bilayer (Seddon and Templer 1995). Therefore, it was proposed that antimicrobial peptides may affect this balance lowering the lamellar to non-lamellar phase boundary, which may lead to membrane rupture in case of bacteria with high content of non-lamellar phase forming lipids (Lohner and Blondelle 2005). Recently, a correlation of non-lamellar phase formation of $E$. coli total lipid extracts and antimicrobial activity of cationic amphipathic peptides, derived from a fragment of human lactoferricin (LF-11), was reported (Zweytick et al. 2008). The peptide-induced 


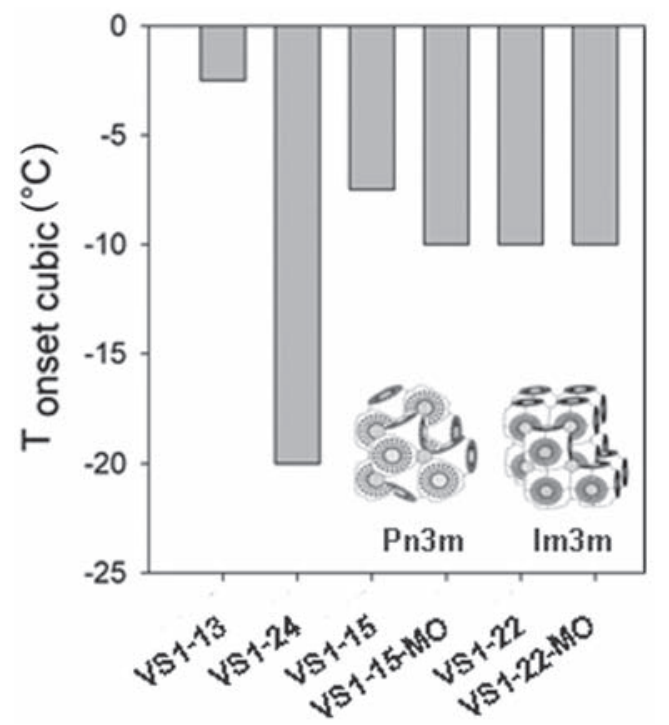

Figure 6. Promotion of cubic structures of $E$. coli total lipid extract by short peptides (8-10 aa) derived from LF-11, a fragment of human lactoferricin at a lipid-to-peptide molar ratio of $25: 1$. Data for VS1-13 and VS1-24 taken from Zweytick et al. (2008). In addition, results from VS1-15 and VS1-22 as well as their $N$-methyloctanoyl analog (VS1-15-MO, VS1-22-MO) are included. The decrease in the onset temperature of cubic phase formation was determined from small-angle X-ray experiments. Scheme of the cubic phases (Pn3m, Im3m) detected are shown in the panel.

structures were identified to belong to the bicontinous cubic phases of space group Pn3m and Im3m as described earlier for $E$. coli lipid extracts in the presence of the antimicrobial peptide gramicidin S (Staudegger et al. 2000). The most active peptides were characterized by a larger hydrophobic volume at the N-terminus than their less active counterpart. Similarly, $\mathrm{N}$-acylated derivatives of these lactoferricin derived peptides were also able to promote cubic phases (Fig. 6). While the bulky hydrophobic $\mathrm{N}$-terminus seems to play an important role in the promotion of these non-lamellar structures, in case of gramicidin S the capability to strongly promote negative curvature and thus cubic phase formation was proposed to be due to the limited flexibility of the $\beta$-turn of gramicidin $S$ as well as to the clustered location of the ornithine side chains.

$\mathrm{PE}$, a major component of both the inner and outer leaflet of Gram-negative bacteria, can adopt non-lamellar structures, such as the inverted hexagonal $\left(\mathrm{H}_{\mathrm{II}}\right)$ and cubic phases (Siegel and Banschbach 1990; Rappolt et al. 2003). The phase transition temperature, depending on the acyl chain composition (e.g. Lohner 1996), was markedly decreased in the presence of a number of antimicrobial peptides (Lohner and Blondelle 2005 and references therein; Pabst et al. 2008). Alamethicin promoted cubic phase formation, when incorporated in small amounts in dielaidoyl PE (Keller et al. 1996), which was suggested to be due to changes regarding the thickness and/or flexibility of the lipid bilayer, because in diphytanoyl PC model membranes this peptide causes membrane thinning with a concomitant increase in chain disorder over a large area (Ludtke et al. 1995; Wu et al. 1995). Interestingly, membrane thinning was also observed for E. coli lipid extracts in presence of the lactoferricin derivatives (Zweytick et al. 2008). The decrease in membrane thickness will lead to an increase in the hydrophobic cross-sectional area of the lipid acyl chains. This lateral expansion would further enhance the existing mismatch between the cross-sectional areas of the head group and hydrocarbon side chains of PE, which could be a promotive force for the lipid monolayer to curl.

In the presence of the cytolytic melittin, the fluid to $\mathrm{H}_{\mathrm{II}}$ transition of a mixed chain PE was abolished and only a bilayer structure was observed in the studied temperature range, which was explained by electrostatic repulsion due to the charged peptide (Hickel et al. 2008). Seemingly this does not play a role for the antimicrobial peptide PGLa, which has the same net charge as melittin, but exhibited a strongly reduced bilayer separation as compared to melittin and like protegrin-1 induced cubic phase formation to some extent. This different behavior was explained by shielding of the positive charges of PGLa owing to lipid/peptide pore formation in the fluid phase. In contrast to these observations, some antimicrobial peptides such as nisin (El Jastimi and Lafleur 1999) or a $17 \beta$-amino acid oligomer (Epand et al. 2003) can stabilize the inverse hexagonal phase of PEs. In case of nisin this was explained in analogy to hydrophobic molecules such as squalene (Lohner et al. 1993) being due to insertion of the large hydrophobic section of nisin (segment 1-19), which will lead to an increase in the hydrophobic volume in the bilayer interior. This in turn will promote negative curvature and hence formation of inverted nonlamellar structures. Similarly it was argued that owing to the penetration depth of a $17 \beta$-amino acid oligomer $\mathrm{H}_{\mathrm{II}}$ structures were facilitated by expanding the regions of the bilayer below the pivotal plane more than regions close to the interface. Again this will result in an increase in negative curvature strain (Epand et al. 2003).

The different packing properties of non-lamellar and bilayer stabilizing lipids may have also implications for membrane function. The high lateral hydrocarbon chain pressure exhibited by non-lamellar phase preferring lipids supposedly controls the conformation of integral membrane proteins (de Kruijff 1997). In accordance with this assumption are observations that for example functioning of transport proteins (Bogdanov and Dowhan 1995) as well as protein translocation (Rietveld et al. 1995) was severely impaired in E. coli mutants lacking PE, non-lamellar lipids are often required for functional reconstitution of membrane proteins (Mileykovskaya and Dowhan 2000) and PE is found in pro- 
tein-rich membrane domains (Vanounou 2003). Therefore, antimicrobial peptides that affect the lateral hydrocarbon chain pressure upon insertion may lead as a secondary effect to conformational changes of integral membrane proteins and hence to impairment of membrane function.

\section{Summary and outlook}

The different physical and chemical properties of the lipids found in biological membranes lead to differences of their structural and mechanical properties, which in turn allows antimicrobial peptides to discriminate between bacterial and mammalian cell membranes. Thus, in order to address membrane-peptide interaction adequately the lipid composition has to be elucidated. This is an important goal of lipidomics, which can be achieved now on a qualitative and quantitative level owing to recent developments in analytical instrumentation such as e.g. two-dimensional nano-high-performance liquid chromatography and tandem mass spectroscopy. The studies on liposomes mimicking the more complex biological membranes as described above support this notion. It is evident from these investigations that there is no general molecular mechanism of bacterial killing, but mutually depends on the nature of the peptide and the membrane lipid composition. In particular biophysical studies in this field have demonstrated a complex behavior in terms of membrane perturbation, which depends on several parameters such as lipid acyl chain length and head group, peptide concentration as well as hydrophobic matching of the lipid bilayer core and the peptide, which can lead to different molecular mechanisms of membrane damage and in turn to killing of bacterial cells. It is therefore a prerequisite to study the properties of pure lipids or lipid mixtures in detail, in order to be able to address the effects observed, when antimicrobial peptides interact with the lipid matrix. Since there is a wide variety of host defence peptides, but many of them do not posses sufficient activity and/or selectivity, this knowledge will help to optimize peptides to fine-tune their selective interaction with bacterial cell membranes in order to get a highly active and specific peptide that can be used in combination with or preferably without conventional antibiotics. Such a strategy is expected to yield novel antibiotic compounds that can be used in combination with or preferably without conventional antibiotics and that are characterized by improved properties in respect of selectivity and thus reduced toxicity as well as of hindered development of drug resistance owing to the lack of need of a specific receptor molecule.

Acknowledgement. The author would like to express his sincere thanks to Pavol Balgavý for the expert guidance in his early NMR work and for the many stimulating discussions both on a professional and personal level.

\section{References}

Arouri A., Dathe M., Blume A. (2009): Peptide induced demixing in PG/PE lipid mixtures: A mechanism for the specificity of antimicrobial peptides towards bacterial membranes? Biochim. Biophys. Acta 1788, 650-659; doi:10.1016/ j.bbamem.2008.11.022

Balgavý P., Uhríková D., Gallová J., Lohner K., Degovics G. (1993): Interaction of tertiary amine anesthetics with phosphatidylcholine bilayers. Prog. Coll. Polym. Sci. 93, 184-185; doi:

Balgavý P., Devínsky F. (1996): Cut-off effects in biological activities of surfactants. Adv. Colloid Interface Sci. 66, 23-63; doi:10.1016/0001-8686(96)00295-3

Balgavý P., Uhríková D., Karlovská P., Dubničková M., Kučerka N., Devínsky F., Lacko I., Čižmárik J., Lohner K., Degovics G., Rapp G., Yaradaikin S., Kiselev M., Islamov A. K., Gordeliy V. I. (2001): X-ray diffraction and neutron scattering studies of amphiphile - lipid bilayer organization. Cell. Mol. Biol. 6, 283-290

Bechinger B., Lohner K. (2006): Detergent-like actions of linear amphipathic antimicrobial peptides. Biochim. Biophys. Acta 1758, 1529-1539; doi:10.1016/j.bbamem.2006.07.001

Bevers E. M., Comfurius P., Dekkers D. W. C., Zwaal R. F. A. (1999): Lipid translocation across the plasma membrane of mammalian cells. Biochim. Biophys. Acta 1439, 317-330

Bogdanov M., Dowhan W. (1995): Phosphatidylethanolamine is required for in vivo function of the membrane-associated lactose permease of Escherichia coli. J. Biol. Chem. 270, 732-739; doi:10.1074/jbc.270.2.732

Boman H. G. (1991): Antibacterial peptides: key components needed in immunity. Cell 65, 205-207; doi:10.1016/00928674(91)90154-Q

Boman H. G. (2003): Antibacterial peptides: basic facts and emerging concepts. J. Intern. Med. 254, 197-215; doi:10.1046/ j.1365-2796.2003.01228.x

Breukink E., van Kraaij C., Demel A. R., Peelen T., Siezen R., de Kruijff B., Kuipers O. (1997): The C-terminal region of nisin is responsible for the initial interaction of nisin with the target membrane. Biochemistry 36, 6968-6976; doi:10.1021/bi970008u

Chang S., Sievert D. M., Hageman J. C., Boulton M. L., Tenover F. C., Downes F. P., Shah S., Rudrik J. T., Pupp G. R., Brown W. J., Cardo D., Fridkin S. K. (2003): Infection with vancomycin-resistant Staphylococcus aureus containing the vanA resistance gene. N. Engl. J. Med. 348, 1342-1347; doi:10.1056/NEJMoa025025

Chen F. Y., Lee M. T., Huang H. W. (2003): Evidence for membrane thinning effect as the mechanism for peptide-induced pore formation. Biophys. J. 84, 3751-3758; doi:10.1016/ S0006-3495(03)75103-0

Cullis P. R., de Kruijff B. (1979): Lipid polymorphism and the functional roles of lipids in biological membranes. Biochim. Biophys. Acta 559, 399-420

de Kruijff B. (1997): Biomembranes. Lipids beyond the bilayer. Nature 386, 129-130; doi:10.1038/386129a0

Dathe M., Meyer J., Beyermann M., Maul B., Hoischen C., Bienert M. (2002): General aspects of peptide selectivity towards 
lipid bilayers and cell membranes studied by variation of the structural parameters of amphipathic helical model peptides. Biochim. Biophys. Acta 1558, 171-186; doi:10.1016/S0005-2736(01)00429-1

de Planque M. R., Greathouse D. V., Koeppe R. E., Schafer H., Marsh D., Killian J. A. (1998): Influence of lipid/peptide hydrophobic mismatch on the thickness of diacylphosphatidylcholine bilayers. A 2H NMR and ESR study using designed transmembrane $\alpha$-helical peptides and gramicidin A. Biochemistry 37, 9333-9345; doi:10.1021/ bi980233r

Devínsky F., Kopecká-Leitmanová A., Šeršeň F., Balgavý P. (1990): Cut-off effect in antimicrobial activity and in membrane perturbation efficiency of the homologous series of N,N-dimethylalkylamine oxides. J. Pharm. Pharmacol. 42, 790-794

El Jastimi R., Lafleur M. (1999): Nisin promotes the formation of non-lamellar inverted phases in unsaturated phosphatidylethanolamine. Biochim. Biophys. Acta. 1418, 97-105; doi:10.1016/S0005-2736(99)00027-9

Epand R. F., Umezawa N., Porter E. A., Gellman S. H., Epand R. M. (2003): Interactions of the antimicrobial $\beta$-peptide $\beta$-17 with phospholipid vesicles differ from membrane interactions of magainins. Eur. J. Biochem. 270, 1240-1248; doi:10.1046/j.1432-1033.2003.03484.x

Epand R. F., Schmitt M. A., Gellman S. H., Epand R. M. (2006): Role of membrane lipids in the mechanism of bacterial species selective toxicity by two $\alpha / \beta$-antimicrobial peptides. Biochim. Biophys. Acta 1758, 1343-1350; doi:10.1016/ j.bbamem.2006.01.018

Epand R. F., Mowery B. P., Lee S. E., Stahl S. S., Lehrer R. I., Gellman S. H., Epand R. M. (2008a): Dual mechanism of bacterial lethality for a cationic sequence-random copolymer that mimics host-defense antimicrobial peptides. J. Mol. Biol 379, 38-50; doi:10.1016/j.jmb.2008.03.047

Epand R. M., Rotem S., Mor A., Berno B., Epand R. F. (2008b): Bacterial membranes as a predictor of antimicrobial potency. J. Am. Chem. Soc. 130, 14346-14352; doi:10.1021/ ja8062327

Epand R. M., Epand R. F. (2009): Lipid domains in bacterial membranes and the action of antimicrobial agents. Biochim. Biophys. Acta 1788, 289-294; doi:10.1016/ j.bbamem.2008.08.023

Enserink M. (2003): Infectious diseases. Resistant staph finds new niches. Science 299, 1639-1641; doi:10.1126/ science. 299.5613 .1639

Fluit A. C., Schmitz F.-J. (2003): MRSA: Current Perspectives. Caister Academic Press, Wymondham, Norfolk, U.K.

Ganz T., Lehrer R. I. (2001): Antimicrobial peptides in innate immunity. In: Development of Novel Antimicrobial Agents: Emerging Strategies. (Ed. K. Lohner), pp. 139-147, Horizon Scientific Press, Wymondham, Norfolk, U.K.

Glover R. E., Smith R. R., Jones M. V., Jackson S. K., Rowlands C. C. (1999): An EPR investigation of surfactant action on bacterial membranes. FEMS Microbiol. Lett. 177, 57-62; doi:10.1111/j.1574-6968.1999.tb13713.x

Jean-Francois F., Castano S., Desbat B., Odaert B., Roux M., MetzBoutigue M. H., Dufourc E. J. (2008): Aggregation of cateslytin beta-sheets on negatively charged lipids promotes rigid membrane domains. A new mode of action for antimicrobial peptides? Biochemistry 47, 6394-6402; doi:10.1021/bi800448h

Hale J. D., Hancock R. E. (2007): Alternative mechanisms of action of cationic antimicrobial peptides on bacteria. Expert Rev. Anti Infect. Ther. 5, 951-959; doi:10.1586/14787210.5.6.951

Hancock R. E., Rozek A. (2002): Role of membranes in the activities of antimicrobial cationic peptides. FEMS Microbiol. Lett. 206, 143-149; doi:10.1111/j.1574-6968.2002.tb11000.x

Hasper H. E., Kramer N. E., Smith J. L., Hillman J. D., Zachariah C., Kuipers O. P., de Kruijff B., Breukink E. (2006): An alternative bactericidal mechanism of action for lantibiotic peptides that target lipid II. Science 313, 1636-1637; doi:10.1126/science.1129818

Hawkey P. M. (2008): Molecular epidemiology of clinically significant antibiotic resistance genes. Br. J. Pharmacol. 153, S406-413; doi:10.1038/sj.bjp.0707632

Hays L. M., Crowe J. H., Wolkers W., Rudenko S. (2001): Factors affecting leakage of trapped solutes from phospholipid vesicles during thermotropic phase transitions. Cryobiology 42, 88-102; doi:10.1006/cryo.2001.2307

He K., Ludtke S. J., Heller W. T., Huang H. W (1996): Mechanism of alamethicin insertion into lipid bilayers. Biophys. J. 71, 2669-2679; doi:10.1016/S0006-3495(96)79458-4

Heller W. T., Waring A. J., Lehrer R. I., Harroun T. A., Weiss T. M., Yang L., Huang H. W. (2000): Membrane thinning effect of the beta-sheet antimicrobial protegrin. Biochemistry 39, 139-145; doi:10.1021/bi991892m

Hickel A., Danner S., Amenitsch H., Degovics G., Rappolt M., Lohner K., Pabst G. (2008): Influence of antimicrobial peptides on the formation of nonlamellar lipid mesophases. Biochim. Biophys. Acta 1778, 2325-2333; doi:10.1016/j.bbamem.2008.05.014

Howe R. A., Monk A., Wootton M., Walsh T. R., Enright M. C. (2004): Vancomycin susceptibility within methicillinresistant Staphylococcus aureus lineages. Emerg. Infect. Dis. 10, 855-857

Huang H. W. (2006): Molecular mechanism of antimicrobial peptides: the origin of cooperativity. Biochim. Biophys. Acta 1758, 1292-1302; doi:10.1016/j.bbamem.2006.02.001

Hrubšová A., Karlovská J., Devínsky F., Lacko I., Balgavý P. (2003): Solubilization of unilamellar egg yolk phosphatidylcholine liposomes by $\mathrm{N}$-alkyl-N,N-dimethylamine $\mathrm{N}$-oxides. Ceska Slov. Farm. 52, 299-305 (in Czech)

Israelachvili J. N., Marcelja S., Horn R. G. (1980): Physical principles of membrane organization. Q. Rev. Biophys. 13, 121-200; doi:10.1017/S0033583500001645

Karlovská J., Lohner K., Degovics G., Lacko I., Devínsky F., Balgavý P. (2004): Effects of non-ionic surfactants Nalkyl-N,N-dimethylamine-N-oxides on the structure of a phospholipid bilayer: small-angle X-ray diffraction study. Chem. Phys. Lipids 129, 31-41; doi:10.1016/j.che mphyslip.2003.11.003

Keller S. L., Gruner S. M., Gawrisch K. (1996): Small concentrations of alamethicin induce a cubic phase in bulk phosphatidylethanolamine mixtures. Biochim. Biophys. Acta 1278, 241-246; doi:10.1016/0005-2736(95)00229-4 
Killian J. A. (2003): Synthetic peptides as models for intrinsic membrane proteins. FEBS Lett. 555, 134-138; doi:10.1016/S0014-5793(03)01154-2

Konovalov O., Myagkov I., Struth B., Lohner K. (2002): Lipid discrimination in phospholipid monolayers by the antimicrobial frog skin peptide, PGLa. A synchrotron X-ray grazing incidence and reflectivity study. Eur. Biophys. J. 31, 428-437; doi:10.1007/s00249-002-0233-3

Kragh-Hansen U., le Maire M., Moller J. V. (1998): The mechanism of detergent solubilization of liposomes and proteincontaining membranes. Biophys. J. 75, 2932-2946; doi:10.1016/S0006-3495(98)77735-5

Latal A., Lehrer R. I., Harwig S. S., Lohner K. (1996): Interaction of enantiomeric protegrins with liposomes. Prog. Biophys. Mol. Biol. 65, 121

Latal A., Degovics G., Epand R. F., Epand R. M., Lohner K. (1997): Structural aspects of the interaction of peptidyl-glycylleucine-carboxyamide, a highly potent antimicrobial peptide from frog skin, with lipids. Eur. J. Biochem. 248, 938-946; doi:10.1111/j.1432-1033.1997.00938.x

Li C., Salditt T. (2006): Structure of magainin and alamethicin in model membranes studied by $\mathrm{x}$-ray reflectivity. Biophys. J. 91, 3285-3300; doi:10.1529/biophysj.106.090118

Lohner K. (1991): Effects of small organic molecules on phospholipid phase transitions. Chem. Phys. Lipids 57, 341-362 doi:10.1016/0009-3084(91)90085-P

Lohner K., Degovics G., Laggner P., Gnamusch E., Paltauf F. (1993): Squalene promotes the formation of non-bilayer structures in phospholipid model membranes. Biochim. Biophys. Acta 1152, 69-77; doi:10.1016/00052736(93)90232-O

Lohner K. (1996): Is the high propensity of ethanolamine plasmalogens to form non-lamellar lipid structures manifested in the properties of biomembranes? Chem. Phys. Lipids 81, 167-184; doi:10.1016/0009-3084(96)02580-7

Lohner K., Latal A., Lehrer R. I., Ganz T. (1997): Differential scanning microcalorimetry indicates that human defensin, HNP-2, interacts specifically with biomembrane mimetic systems. Biochemistry 36, 1525-1531; doi:10.1021/bi961300p

Lohner K., Prenner E. J. (1999): Differential scanning calorimetry and X-ray diffraction studies of the specificity of the interaction of antimicrobial peptides with membranemimetic systems. Biochim. Biophys. Acta 1462, 141-156; doi:10.1016/S0005-2736(99)00204-7

Lohner K. (2001a): Development of Novel Antimicrobial Agents: Emerging Strategies. Horizon Scientific Press, Wymondham, Norfolk, U.K.

Lohner K. (2001b): The role of membrane lipid composition in cell targeting of antimicrobial peptides. In: Development of Novel Antimicrobial Agents: Emerging Strategies. pp. 149-165, Horizon Scientific Press, Wymondham, Norfolk, U.K.

Lohner K., Blondelle S. E. (2005): Molecular mechanisms of membrane perturbation by antimicrobial peptides and the use of biophysical studies in the design of novel peptide antibiotics. Comb. Chem. High Throughput Screen. 8, 239-255; doi:10.2174/1386207053764576
Ludtke S., He K., Huang H. W. (1995): Membrane thinning caused by magainin 2. Biochemistry 34, 16764-16769doi:10.1021/ bi00051a026

Ludtke S. J., He K., Heller W. T., Harroun T. A., Yang L., Huang H. W. (1996): Membrane pores induced by magainin. Biochemistry 35, 13723-13728; doi:10.1021/bi9620621

Matsumoto K., Kusaka J., Nishibori A., Hara H. (2006): Lipid domains in bacterial membranes. Mol. Microbiol. 61, 1110-1117; doi:10.1111/j.1365-2958.2006.05317.x

Matsuzaki K., Murase O., Miyajima K. (1995): Kinetics of pore formation by an antimicrobial peptide, magainin 2, in phospholipid bilayers. Biochemistry 34, 12553 -12559; doi:10.1021/bi00039a009

Matsuzaki K., Murase O., Fujii N., Miyajima K. (1996): An antimicrobial peptide, magainin 2 , induced rapid flip-flop of phospholipids coupled with pore formation and peptide translocation. Biochemistry 35, 11361-11368; doi:10.1021/bi960016v

Matsuzaki K., Sugishita K., Harada M., Fujii N., Miyajima K. (1997): Interactions of an antimicrobial peptide, magainin 2, with outer and inner membranes of Gram-negative bacteria. Biochim. Biophys. Acta 1327, 119-130; doi:10.1016/ S0005-2736(97)00051-5

Matsuzaki K., Sugishita K., Ishibe N., Ueha M., Nakata S., Miyajima K., Epand R. M. (1998): Relationship of membrane curvature to the formation of pores by magainin 2. Biochemistry 37, 11856-11863; doi:10.1021/bi980539y

Matsuzaki K. (2001): Molecular mechanisms of membrane perturbation by antimicrobial peptides. In: Development of Novel Antimicrobial Agents: Emerging Strategies. (Ed. K. Lohner), pp. 167-181, Horizon Scientific Press, Wymondham, Norfolk, U.K.

McElhaney R. N. (1992): Membrane structure. In: Mycoplasmas: Molecular Biology and Pathogenesis. (Eds. J. Maniloff, R. N. McElhaney, L. R. Finch and J. B. Baseman), pp. 113-155, American Society for Microbiology, Washington DC

Mileykovskaya E., Dowhan W. (2005): Role of membrane lipids in bacterial division-site selection. Curr. Opin. Microbiol. 8, 135-142; doi:10.1016/j.mib.2005.02.012

Mileykovskaya E., Dowhan W. (2000): Visualization of phospholipid domains in Escherichia coli by using the cardiolipinspecific fluorescent dye 10-N-nonyl acridine orange. J. Bacteriol. 182, 1172-1175; doi:10.1128/JB.182.4.11721175.2000

Mileykovskaya E., Sun Q., Margolin W., Dowhan W. (1998): Localization and function of early cell division proteins in filamentous Escherichia coli cells lacking phosphatidylethanolamine. J. Bacteriol. 180, 4252-4257

Morein S., Andersson A., Rilfors L., Lindblom G. (1996): Wildtype Escherichia coli cells regulate the membrane lipid composition in a "window" between gel and non-lamellar structures. J. Biol. Chem. 271, 6801-6809; doi:10.1074/ jbc.271.12.6801

Nakamura T., Furunaka H., Miyata T., Tokunaga F., Muta T., Iwanaga S., Niwa M., Takao T., Shimonishi Y. (1988): Tachyplesin, a class of antimicrobial peptide from the hemocytes of the horseshoe crab (Tachypleus triden- 
tatus). Isolation and chemical structure. J. Biol. Chem. 263, 16709-16713

Nordberg P., Monnet D. L., Cars O. (2005): Antibacterial Drug Resistance: Options for Concerned Action. WHO, Department of Medicines Policy and Standards

Norris V., Fishov I. (2001): Hypothesis: membrane domains and hyperstructures control bacterial division. Biochimie 83, 91-97; doi:10.1016/S0300-9084(00)01203-7

Oren Z., Shai Y. (2001): Molecular mechanism of cell selectivity by linear amphipatic $\alpha$-helical and diasteriomeric antimicrobial peptides. In: Development of Novel Antimicrobial Agents: Emerging Strategies. (Ed. K. Lohner), pp. 183-204, Horizon Scientific Press, Wymondham, Norfolk, U.K.

Pabst G., Danner S., Podgornik R., Katsaras J. (2007): Entropydriven softening of fluid lipid bilayers by alamethicin. Langmuir 23, 11705-11711; doi:10.1021/la701586c

Pabst G., Grage S., Danner-Pongratz S., Jing W., Ulrich A. S., Watts A., Lohner K., Hickel A. (2008): Membrane thickening by the antimicrobial peptide PGLa. Biophys. J. 95, 5779-5788; doi:10.1529/biophysj.108.141630

Powers J. P. S., Hancock R. E. W. (2003): The relationship between peptide structure and antibacterial activity. Peptides $\mathbf{2 4}$ 1681-1691; doi:10.1016/j.peptides.2003.08.023

Rappolt M., Hickel A., Bringezu F., Lohner K. (2003): Mechanism of the lamellar/inverse hexagonal phase transition examined by high resolution x-ray diffraction. Biophys. J. 84, 3111-3122; doi:10.1016/S0006-3495(03)70036-8

Rietveld A. G., Koorengevel M. C., de Kruijff B. (1995): Non-bilayer lipids are required for efficient protein transport across the plasma membrane of Escherichia coli. EMBO J. 14, 5506-5513

Rilfors L., Wieslander A., Lindblom G. (1993): Mycoplasma cell membranes. In: Subcellular Biochemistry. (Ed. S. Rottem and I. Kahane), Vol. 20, pp. 109-166, Plenum Press, New York

Rothman J. E., Leonard J. (1977): Membrane asymmetry. Science 195, 743-753; doi:10.1126/science. 402030

Rowe E. S. (1983): Lipid chain length and temperature dependence of ethanol-phosphatidylcholine interactions. Biochemistry 22, 3299-3305; doi:10.1021/bi00283a001

Seddon J. M., Templer R. H. (1995): Polymorphism of lipid-water systems. In: Handbook of Biological Physics: Structure and Dynamics of Membranes. (Eds. R. Lipowsky and E. Sackmann), pp. 97-160, Elsevier SPC, Amsterdam

Sevcsik E., Pabst G., Jilek A., Lohner K. (2007): How lipids influence the mode of action of membrane-active peptides. Biochim. Biophys. Acta 1768, 2586-2595; doi:10.1016/ j.bbamem.2007.06.015

Sevcsik E., Pabst G., Richter W., Danner S., Amenitsch H., Lohner K. (2008): Interaction of LL-37 with model membrane systems of different complexity: influence of the lipid matrix. Biophys J. 94, 4688-4699; doi:10.1529/ biophysj.107.123620

Shai Y. (2002): Mode of action of membrane active antimicrobial peptides. Biopolymers 66, 236-248; doi:10.1002/ bip. 10260
Siegel D. P., Banschbach J. L. (1990): Lamellar/inverted cubic (La/QII) phase transition in N-methylateddioleoylphosphatidylethanolamine. Biochemistry 29, 5975-5981; doi:10.1021/bi00477a014

Simon S. A., Mclntosh T. J. (1984): Interdigitated hydrocarbon chain packing causes the biphasic transition behavior in lipid/alcohol suspensions. Biochim. Biophys. Acta 773, 169-172; doi:10.1016/0005-2736(84)90562-5

Smith R. D., Coast J. (2002): Antimicrobial resistance: a global response. Bull. WHO 80, 126-133

Staudegger E., Prenner E. J., Kriechbaum M., Degovics G., Lewis R. N. A. H., McElhaney R. N., Lohner K. (2000): X-ray studies on the interaction of gramicidin $S$ with microbial lipid extracts: evidence for cubic phase formation. Biochim. Biophys. Acta 1468, 213-230; doi:10.1016/S00052736(00)00260-1

Strandberg E., Wadhwani P., Tremouilhac P., Durr U. H., Ulrich A. S. (2006): Solid-state NMR analysis of the PGLa peptide orientation in DMPC bilayers: structural fidelity of $2 \mathrm{H}-$ labels versus high sensitivity of 19F-NMR. Biophys. J. 90, 1676-1686; doi:10.1529/biophysj.105.073858

Uhríková D., Kučerka N., Islamov A., Gordeliy V., Balgavý P. (2001): Small-angle neutron scattering study of N-dodecyl$\mathrm{N}, \mathrm{N}$-dimethylamine $\mathrm{N}$-oxide induced solubilization of dioleoylphosphatidylcholine bilayers in liposomes. Gen. Physiol. Biophys. 20, 183-189

Vanounou S., Parola A. H., Fishov I. (2003): Phosphatidylethanolamine and phosphatidylglycerol are segregated into different domains in bacterial membrane. A study with pyrene-labelled phospholipids. Mol. Microbiol. 49, 1067-1079; doi:10.1046/j.1365-2958.2003.03614.x

White S. H., Wimley W. C., Selsted M. E. (1995): Structure, function, and membrane integration of defensin. Curr. Opin. Struct. Biol. 5, 521-527; doi:10.1016/0959-440X(95)80038-7

Wu Y., He K., Ludtke S. J., Huang H. W. (1995): X-ray diffraction study of lipid bilayer membranes interacting with amphiphilic helical peptides: diphytanoyl phosphatidylcholine with alamethicin at low concentrations. Biophys. J. 68, 2361-2369; doi:10.1016/S0006-3495(95)80418-2

Yang L., Harroun T. A., Weiss T. M., Ding L., Huang H. W. (2001): Barrel-stave model or toroidal model? A case study on melittin pores. Biophys. J. 81, 1475-1485; doi:10.1016/ S0006-3495(01)75802-X

Yorek M. A. (1993): Biological distribution. In: Phospholipids Handbook. (Ed. G. Cevc), pp. 745-775, Marcel Dekker, Inc., New York

Zasloff M. (2002): Antimicrobial peptides of multicellular organisms. Nature 415, 389-395; doi:10.1038/415389a

Zweytick D., Tumer S., Blondelle S. E., Lohner K. (2008): Membrane curvature stress and antibacterial activity of lactoferricin derivatives. Biochem. Biophys. Res. Commun. 369, 395-400; doi:10.1016/j.bbrc.2008.01.176

Received: April 27, 2009

Final version accepted: May 5, 2009 